\title{
DOES RATIO OF WIDTH TO LENGTH OF LEFT ATRIAL APPENDAGE DETERMINE THE OCCURRENCE OF CEREBROVASCULAR STROKE EVENT IN BOTH
}

\section{GENDERS?}

\author{
Oruganti Harish, Jabeen, Mantha Srinivas.
}

\begin{abstract}
Objective : To see the Left atrial appendage size (width and length) in ischemic cerebrovascular accident (CVA) patients. Design and method: Transesophageal echocardiography (TEE) was done in ischemic CVA patients after initial stabilization. We compared width length ratio(WLR) calculated from the average of width and length of LAA observed in earlier study by John $P$ et al as controls. We chose this autopsy study as controls, as it is not possible to have TEE data in normal subjects.

Results : Study group includes 143 patients (F:M::37:106) and control group was 400 subjects (F:M::200:200) from the previous study. The mean \pm std of width and length of LAA in females and males in study group were 1.99 $\pm 0.67,2.397 \pm 0.58$ and $2.19 \pm 0.73,2.49 \pm 0.66$ respectively. In females, WLR is more $(0.83 \pm 0.37)$ in study group than in control group $(0.66 \pm 0.26)$ which is statistically significant $(z=4.06, P<0.000001)$. So also for males (study group: control group :: $0.88 \pm 0.39: 0.71 \pm 0.28$ ) which is also statistically significant $(z=7.03, P<0.000001)$. So, broad and short LAA could determine the formation and dislodgement of thrombus resulting in embolic stroke in both sexes.

In conclusion, higher the width length ratio of left atrial appendage greater chances of embolic stoke.
\end{abstract}

KEY WORDS: Left atrial appendage, CVA. TEE

\section{INTRODUCTION}

Stroke risk is influenced by multitude of factors. Loss of contractile function in the LAA can lead to local stasis and thrombus formation, which may then embolize into the systemic circulation[1]. Most strokes in patients with

Article received on 25 March2016, published on 30 April 2016.

Oruganti Harish ${ }^{1}$, Jabeen ${ }^{2}$, Mantha Srinivas ${ }^{3}$.

${ }^{1}$ Senior resident, Department of cardiology, NIMS, India

${ }^{2}$ Asso. Prof of Neurology

${ }^{3}$ Prof of Anaethesia.

Corresponding author: Oruganti Harish

Email: harishcardiologynims@gmail.com atrial fibrillation (AF) arise from thrombus formation in left atrial appendage (LAA)[2]. Morphological features of the LAA may influence stroke risk. Larger LAA neck diameter and LAA depth have been associated with a higher prevalence of prior stroke in AF patients [3]. Various morphological features like LAA width, length, shape, extent of trabeculations influence the stroke risk. We tried to study the influence of width length ratio of LAA on stroke risk.

\section{MATERIALS AND METHODS:}

Study patients : We collected the transesophageal Echocardiographic (TEE) data of the Ischemic cerebrovascular accident (CVA) patients came to cardiology echo room ( from inpatients of neurology) to know the source of embolism between Jan 2014 to Dec 2014. The duration of event (CVA) to TEE is variable as TEE was done after stabilization of patients after the event with the discretion of the neurologist. We included only those patients who can swallow and could complete the TEE procedure. We collected the demographic and risk factor features of these patients. We analyzed data according to gender also.

Materials: We used Philips iE33 2D Echocardiogram Machine with adult omniplane TEE probe. TEE was done in left lateral position after usage of local xylocaine spray for throat and xylocaine jelly on the TEE probe. We noted the all cardiac chambers, valves and great artery anatomy and function. In addition special attention was given to the left atrial appendage size, length (L), width $(\mathrm{W}), \mathrm{W} / \mathrm{L}$ ratio, no of lobules and presence or absence of clot in different angles $(30,45,90$, $135^{\circ}$ ) recorded.

As we cannot get the details of normal LAA by TEE, we have taken the historic controls from Veinot et al autopsy study. In this study they mentioned the length, 
width of LAA in different age groups. So, we calculated the $\mathrm{W} / \mathrm{L}$ ratio of these normal LAAs from that study.

Statistical methods: Data analysis was performed using Minitab version 16 software. For comparison and to know the $\mathrm{p}$ value for W/L ration we used Fisher's exact test. Continuous variables were expressed as mean $\pm \mathrm{SD}$ .Results with a p value $<0.05$ is considered to be significant.

\section{RESULTS:}

The 143 consecutive patients (F: M::37:106) admitted at Nizam's institute of medical sciences, Hyderabad who recovered from ischemic stroke were enrolled into our study. Demographic features of the study population is given in Table 1. TEE was done in all these patients after stabilization. 500 (F:M::250:250) from veinot etal. Study was taken as controls. In study they had taken 25 males and 25 females for each decade over 10 decades.

Table 1: Demographic features of CVA patients.

\begin{tabular}{|l|l|}
\hline Variable & Results \\
\hline Age (years) & $56.2 \pm 9.7$ \\
\hline No of patients & 143 \\
\hline M:F & $2.9: 1$ \\
\hline Hypertension & $113(79 \%)$ \\
\hline Diabetes & $94(65.7 \%)$ \\
\hline
\end{tabular}

Mean duration of event of CVA to TEE was 5.2 \pm 2.5 days. In whom we could pass the TEE probe but could not complete the study are excluded. width, length of LAA was assessed by TEE and WLR was derived. On TEE, the widest anatomic orifice (from the circumflex artery inferiorly to a point 1 to $2 \mathrm{~cm}$ inside the tip of the pulmonary vein ridge superiorly) and the LAA depth were recorded. We measured the LAA orifice and depth at 90 and 135, because these usually produce the largest dimensions; Measurements were taken when LAA width was greatest, which usually occurs at end-systole (According to Ryan J. Spencer study - 2015 article).

Mean and standard deviation of each measurement by sex along with width and length of study patients and controls are shown in Table 2. Width of LA appendage in the study population is more compared to controls which is significant.

In females, WLR is more $(0.83 \pm 0.37)$ in study group than in control group $(0.66 \pm 0.26)$ which is statistically significant $(\mathrm{P}=0.00)$. So also for males (study group: control group:: $0.88 \pm 0.39: 0.71 \pm 0.28$ ) which is also statistically significant $(p=0.01)$. Basically the width of LAA is significantly varying in diseased and controls, so there is difference event in WLR also. This true in both genders.

\section{DISCUSSION:}

The LAA derives from the primordial left atrium (LA), which is formed mainly by the adsorption of the primordial pulmonary veins and their branches [4]. It is a finger-like projection from the main body of the LA. The junction is fairly well defined by a narrowing at the orifice of the appendage.

LAA does not seem to be just an embryologic remnant, a useless appendage. The LAA is responsible for several functions: it acts as a reservoir during left ventricular systole, a conduit for blood transiting from the pulmonary veins to the left ventricle during early diastole, an active contractile chamber that augments left ventricular filling in late diastole, and a suction source that refills itself in early systole[5]. With transesophageal evaluations, Lueng et al.[6]and manning et al[7] Reported that up to $98 \%$ of atrial thrombi occurring during AF derive from the LAA.

Although the offending thrombi could have embolized before LAA assessment, additional data suggest that not all strokes in AF may be prevented by LAA-targeted therapies. As many as $25 \%$ of strokes in AF patients can be linked to intrinsic cerebrovascular disease[3].

We evaluated width length ratio of the study subjects and found that patients with wider and shorter LAA were at higher risk of CVA. This could be due to low flow velocity and increased stasis in LAA. A reduced LAA peak flow velocity is considered as one of the strongest independent predictors of an increased thromboembolic risk $[8,9]$.

Study limitations:

This study comparison is done with post mortem controls and they could have lower dimensions due to contractility due to preservation. Other factors are also important in estimating CVA risk like orifice area, flow velocity, appendage morphology and number of pectinate muscles which were not evaluated in this study[10]. 
Table 2: Table showing dimensions of LA appendage

\begin{tabular}{|l|l|l|l|l|l|l|}
\hline Parameter & $\begin{array}{l}\text { Females } \\
(\mathrm{CVA})\end{array}$ & $\begin{array}{l}\text { Females } \\
(\text { controls })\end{array}$ & P value & $\begin{array}{l}\text { Males } \\
(\mathrm{CVA})\end{array}$ & $\begin{array}{l}\text { Males } \\
(\text { controls })\end{array}$ & P value \\
\hline WLR & $0.83 \pm 0.37$ & $0.66 \pm 0.26$ & 0.000 & $0.88 \pm 0.39$ & $0.71 \pm 0.28$ & 0.01 \\
\hline Width & $1.99 \pm 0.67$ & $1.66 \pm 0.48$ & 0.006 & $2.19 \pm 0.73$ & $1.83 \pm 0.73$ & 0.000 \\
\hline Length & $2.397 \pm 0.58$ & $2.53 \pm 0.78$ & 0.2 & $2.49 \pm 0.66$ & $2.59 \pm 0.66$ & 0.2 \\
\hline
\end{tabular}

\section{CONCLUSION:}

Patients with shorter and broader LAA could be at high risk of CVA. Therefore evaluation of all at risk patients for LAA dimensions could be an option for deciding thrombotic risk. This can explain easy embolization of the already thrombus with wider neck than narrow and constricted

\section{REFERENCES:}

1. Matthew J. Price, MD; Miguel Valderrábano, MD .New Drugs and Technologies. Left Atrial Appendage Closure to Prevent Stroke in Patients With Atrial Fibrillation. Circulation.2014; 130: 202212.

2. Beinart R, Heist EK,,Newell JB,Holmvang G,Ruskin JN, Mansour M. Left atrial appendage dimensions predict the risk of stroke/TIA in patients with atrial fibrillation. J Cardiovasc Electrophysiol. 2011;22:1015.

3. Khurram, Irfan M., et al. "Relationship between left atrial appendage morphology and stroke in patients with atrial fibrillation." Heart Rhythm 10.12 (2013): 1843-1849

4. L.D. Biase, J.D. Burkhardt, P. Mohanty, et al.Left atrial appendage an underrecognized trigger site of atrial fibrillationCirculation, 122 (2010), pp. 109-118

5. Barbier, Paolo, et al. "Left atrial relaxation and left ventricular systolic function determine left atrial reservoir function." Circulation 100.4 (1999): 427-436.

6. Leung, Dominic YC, et al. "Prognostic implications of left artial spontaneous echo contrast in nonvalvular atrial fibrillation." Journal of the American College of Cardiology 24.3 (1994): 755-762.

7. Manning, Warren J., et al. "Accuracy of transesophageal echocardiography for identifying left atrial thrombi: a prospective, intraoperative study." Annals of Internal Medicine 123.11 (1995): 817-822.

8. Takada, Tatsuro, et al. "Blood flow in the left atrial appendage and embolic stroke in nonvalvular atrial fibrillation." European neurology 46.3 (2001): 148-152.

9. Damiano Regazzoli, Francesco Ancona, Nicola Trevisi, et al., "Left Atrial Appendage: Physiology, Pathology, and Role as a Therapeutic Target," BioMed Research International, vol. 2015, Article ID 205013, 13 pages, 2015. doi:10.1155/2015/205013.

10. Lupercio F, Diaz J, Spinetto P, et al. Left Atrial Appendage Morphology And Stroke Risk In Patients With Atrial Fibrillation: A Meta-Analysis. J Am Coll Cardiol. 2016;67(13_S):713. doi:10.1016/S07351097(16)30714-8. 